\title{
The Influence of Electronic Dictionaries on Vocabulary Knowledge Extension
}

\author{
Mojtaba Rezaei ${ }^{1} \&$ Mohammad Davoudi ${ }^{1}$ \\ ${ }^{1}$ Department of English Language and Literature, Hakim Sabzevari University, Sabzevar, Iran \\ Correspondence: Mohammad Davoudi, Department of English Language and Literature, Hakim Sabzevari \\ University, Sabzevar, Iran. E-mail: davoudi2100@gmail.com
}

Received: March 16, 2016

Accepted: April 9, 2016

Online Published: May 15, 2016

doi:10.5539/jel.v5n3p139

URL: http://dx.doi.org/10.5539/jel.v5n3p139

\begin{abstract}
Vocabulary learning needs special strategies in language learning process. The use of dictionaries is a great help in vocabulary learning and nowadays the emergence of electronic dictionaries has added a new and valuable resource for vocabulary learning. The present study aims to explore the influence of Electronic Dictionaries (ED) Vs. Paper Dictionaries (PD) on vocabulary learning and retention of Iranian EFL learners. Seventy college students formed the participants of the study. Before the treatment, a Preliminary English Test was used for assessing the participants' homogeneity. The participants were assigned to Electronic Dictionary (ED) group and Paper Dictionary (PD) group. The treatment lasted for 15 sessions. Eighty-eight new target words were selected in order to be taught in this study. The ED group participants were asked to use their mobile dictionary (Blue Dict dictionary), that include eight popular different dictionaries. The participants of the PD group used their ordinary Paper Dictionaries for finding the meaning of words. In order to check their short-term and long-term vocabulary learning, both groups took part in an immediate and delayed post-test respectively after the treatment. Based on the t-test results, the participants in ED group outperformed those of PD group. The overall results indicate that EDs can improve vocabulary learning.
\end{abstract}

Keywords: electronic dictionaries, paper dictionaries, vocabulary learning, mobile dictionaries, EFL learners

\section{Introduction}

Vocabulary knowledge is a significant aspect of learning a second or foreign language. Vocabulary size is also one of the determinant factors of language proficiency. However, knowing a word entails knowing many attributes of a word. Nielsen (2010) believes that to know a word implies knowing its form and meaning and a word often enjoys many arrays of meaning. As Ooi and Kim-Seoh (1996, p. 56) point out, "lexical competence implies more than just knowing what a word means".

Tillyer (2003) enumerates the following as various components of knowing a word: part of speech, meanings, spelling, pronunciation and stress, synonyms and antonyms, register and style. Acquiring new words is a primary concern for most EFL learners in order to be a proficient language learner. As Wesche and Paribakht (1999) point out, researchers and language learners both believe that, owing to the prime importance of vocabulary learning, learners have to increase their vocabulary size and learn as many words as they can. According to McCarthy (1990), when words expressing a wide range of meanings are not used, it is impossible to form a meaningful communication.

Some vocabulary researchers (Knight, 1994; Schmitt, 2000) believe that overuse of dictionaries for vocabulary learning impedes comprehension process and hinders short-term memory processes involved in vocabulary learning. Instead, they encourage print exposure in the sense that encountering words in various contexts over time is far more effective and helpful in learning words. Despite researchers' concerns, it is undeniable that a dictionary is a great asset in vocabulary learning if it is used properly since it provides immediate and direct access to various layers of vocabulary knowledge. It can serve a lot of purposes especially in providing the definition of words. Krashen (2003) points out that these are dictionaries that learners carry around, not grammar books. Consequently, nowadays many EFL students are found who are greatly dependent on dictionaries, paper or electronic, for their vocabulary learning. 
There is evidence that vocabulary learning is enhanced for learners who check dictionaries to find the meaning of words while they engage in reading and listening (Hulstijn, Hollander, \& Greidanus, 1996; Knight, 1994; Luppescu \& Day, 1993). The existing literature on vocabulary learning strategies illustrate that language learners can learn new vocabulary on their own by using dictionaries. However, they need to be trained on how to use dictionaries appropriately (Gonzalez, 1999). Moreover, recent studies show that the use of dictionary on the part of the learner facilitates vocabulary learning as well as text comprehension (Hulstijn, Hollander, \& Greidanus, 1996; Knight, 1994; Luppescu \& Day, 1993). Also, consulting a dictionary improves the retention of learned words (Neubach \& Cohen, 1988).

Evidently, there are instances in text comprehension where guessing words from context does not work and there is need for checking the meaning of words in a dictionary. It is not always easy or applicable to engage in lexical inferencing. Some conditions have to be met in the text for leaners to be able to engage in lexical inferencing in order to learn the meaning of new words they encounter in the texts. Some contexts do not yield easily to lexical inferencing. In these cases, consulting a dictionary is a good and helpful remedy (Nation, 2001).

Many researchers (Gu \& Johnson, 1996; Kojic-Sabo \& Lightbown, 1999) have reported that irrespective of variables such as learning contexts or individual differences such as age, proficiency level, and vocabulary size, dictionary use still functions as the primary source of new vocabulary learning. Others (Fan, 2000; Kobayashi, 2006; Schmitt, 1997) have found that many learners find dictionary use helpful in acquiring new words. However, Stahl and Fairbanks (1986) illustrated that it is more advisable to use a combination of dictionary use and guessing from contexts. Nowadays, the availability of electronic dictionaries on the Internet has led to their frequent use for vocabulary learning. This is because electronic dictionaries have the advantages of ease and speed that are missing in paper dictionaries.

Recently, various types of electronic dictionaries supplement the ordinary paper dictionaries and function as additional assets in learning new vocabularies. These dictionaries come in various forms such as mobile dictionaries, online dictionaries, dictionaries on CD-ROMs as well as concordances. They offer unprecedented advantages with features such as ease of access, high speed, multimedia environment, co-references, and a non-leaner approach in giving vocabulary knowledge to the language learner (Nesi, 1999). This new technological tool may influence teachers' decisions on recommendations of dictionaries for leaners. Teachers have to embrace these new types of dictionaries and make proper use of them in their classroom activities and for various pedagogical purposes.

In Asian countries, vocabulary is downplayed in the education curriculum and it does not have its due status (Fan, 2003). In these countries, including Iran, the language teaching curriculum puts emphasis on the four skills (listening, speaking, reading and writing) and little emphasis or time is devoted to language components such as vocabulary and grammar. Hence, much of language learning in these contexts is incidental and little instruction is offered on how to learn new words (Catalan, 2003; Fan, 2003). It is general practice in Asian countries that when a new word or phrase appears in the text that is difficult, the definitions are immediately provided by the teacher. This reduces the burden of vocabulary learning on the part of the learner and decreases the changes for learner autonomy on vocabulary learning.

Living in a technologically driven world, students are clearly affected by the latest technological products. Electronic Dictionaries (EDs) are becoming increasingly popular as new technological tools of vocabulary learning among L2 learners and as technology proceeds they will be used more widely by language learners. Since dictionaries have not been researched extensively in Iran, research into the use of them is relatively a new field. Consequently, there is a paucity of research on the Iranian EFL learners' behavior of dictionary use which merits researchers' attention.

The present study tries to fill the gaps in research studies on dictionary use practices in Iranian EFL context. Owing to the fact that L2 language learners rely heavily on dictionaries for learning new words (Fan, 2003; Gu \& Johnson, 1996; Kojic-Sabo \& Lightbown, 1999; Schmitt, 2000), it is needed to study language learners' dictionary use behavior to meet the demands of language proficiency. Additionally, while there are ample studies on dictionary use in L1 contexts, dictionary use in L2 contexts suffers from lack of sufficient research studies (Cotter, 2009). Given the paucity of research in this respect, the present study seeks to explore dictionary use, paper and electronic, of Iranian EFL learners. 


\subsection{Research Questions}

The following research question is posed in this study to explore the dictionary use behaviors of Iranian L2 learners:

1) Is there any significant difference in the use of electronic vs. paper dictionaries by Iranian EFL learners?

2) Is there any significant difference between males and females in the use of electronic vs. paper dictionaries?

\section{Literature Review}

Many studies have been conducted with regard to the effectiveness of the use of new technology in an educational setting. However, the current research investigates the different impacts of electronic dictionaries compared to Paper Dictionaries (PDs) on the students' achievement in learning and retention of vocabulary. This section discusses different theoretical issues related to dictionary use. It also reviews the research studies conducted in the field and reports their results and findings.

It is suggested by vocabulary experts and researchers that language learners use monolingual dictionaries for their vocabulary learning purposes. In this way, they evade the problem of language interference as well as working with two language systems at the same time (Aldosari \& Mekheimer, 2010). However, this advice is controversial and it is far from conclusive. For example, Mansoor-ul-Haq and Ahmad (2010) is the strong advocate of the use of monolingual dictionaries. He explains that the lack of ability to access a word in speech is primarily due to students' use of bilingual dictionaries. Baxter's $(1980$, p. 325) preference for monolingual dictionaries has been expressed in these words: "whereas a bilingual dictionary tends to encourage the employment of a single lexical item, the monolingual dictionary demonstrates that the definition is an alternative".

According to Baxter (1980), who shares concerns with many language teachers, bilingual dictionaries suffer from the following problems: they encourage translation, they foster the conception of one-to-one correspondence between the words of the two languages, and they do not give a true picture of the syntactic properties of words. By contrast, Thompson (1987) guards against the use of monolingual dictionaries and advocates the use of new types of bilingual dictionaries. He asserts that the problem with monolingual dictionaries is that they still "employ a special register which is not necessarily the most useful or rewarding for learners to be exposed to" (p. 284). This inadequacy makes these dictionaries of little use for beginner and intermediate language learners. He advocates the compilation of new bilingual dictionaries that avoid the notion of one-to-one correspondence between the words of the two languages and provide semantic, syntactic and stylistic information that are not found in traditional bilingual dictionaries.

According to Levow, Oard and Resnik (2005), the main reason that learners prefer bilingual dictionaries over monolingual dictionaries is that learning the meaning of new words becomes much easier when they are supplied in one's mother tongue. Moreover, Nesi and Meara (1994) indicate that the information provided by monolingual dictionaries are partially understood by some and misunderstood by other learners. Furthermore, Kaalep and Mikk (2008) argue that the major problem of monolingual dictionaries is that the language in which the definitions are given are hard to understand by L2 language learners. Additionally, Chen (2011) asserts that bilingual entries are ideal for quick understanding. Chen (2011) reported that learners at beginner and intermediate levels of proficiency resort to bilingual dictionaries when they feel insecure in using monolingual ones. However, vocabulary researchers now advocate the use of "bilingualized dictionaries" that embody the good features of both monolingual and bilingual dictionaries (Hartmann, 1991, p. 79).

There are various types of dictionaries which are categorized on the basis of their mode of presentation. Nesi (2008) classifies dictionaries into monolingual, bilingual, and bilingualized dictionaries. Electronic dictionaries come in three forms: hand-held dictionaries, dictionaries on CD-Rom, and Internet dictionaries. We can classify mobile dictionaries as a subgroup of hand-held dictionaries. The main difference between EDs and paper dictionaries is in their manner of access to vocabulary information. In concrete terms, a paper dictionary presents information in alphabetic and linear structure, and this may present problems to the learners. An ED, however, organizes information in non-linear way so that users do not have to leaf through them to find the relevant entry (Nesi, 2008).

Nesi (2003) examined the benefits of EDs and stated that various types of electronic dictionaries offer audio and visual information and exercises in multimedia format. In fact, the rich information offered by these dictionaries is such that it makes them a reference tool which not only provides information on various aspects of vocabulary knowledge but also serves as a language learning device. Laufer and Hill (2000) point out that the high speed and the ease of access of electronic dictionaries encourage the language learners to make frequent use of them in 
the process of vocabulary learning. They go on to make a significant point that using ED increases the chance of acquiring the look-up words. In contrast, the findings of Laufer and Hill (2000) survey showed that many teachers still prefer their students to use paper dictionaries. Some teachers are concerned that the ease of access related to electronic dictionaries might lead to heavy reliance on these dictionaries on the part of learners. Also, Stirling's (2005) study showed that several teachers complain about electronic dictionaries as inaccurate, noisy, and distracting.

EDs can potentially contribute to language learning and instruction. Over and above the fact that electronic dictionaries play a significant role in vocabulary learning, they also have positive effects on motivation of language learners (Al-Jarf, 2007). It is a truism that learners learn more vocabularies when the practice of vocabulary learning is interesting and appealing. Al-Jarf (2007) illustrated that those students who enjoyed vocabulary learning through the use of electronic dictionaries had the highest gains in vocabulary.

Audio aids stimulate students' vocabulary acquisition in ED. According to Wood (2001, p. 182), "Devices that allow users to click on words to hear them pronounced, and sometimes defined, can enhance understandings about new words". One of the benefits of the use of electronic dictionaries it that they improve students' pronunciation which is usually neglected especially when they engage in self-studying. Moreover, the EDs with sound can be used at home to check the pronunciation of words studied in class, especially for those with limited access to native speakers. Audio aids have the additional advantage of increasing vocabulary recall and retention due to their combination of sounds and text image (Al-Seghayer, 2001). When using an electronic dictionary, leaners can click on the words and listen to the correct pronunciation and stress of the new words and hear the sample sentences that exemplify them in context.

Advances in technology have made the use of visual aids more efficient than before. Many researchers (Al-Jarf, 2007; Al-Seghayer, 2001; Wood, 2001) believe that that visual aids used in electronic dictionaries are more useful than the use of paper dictionaries due to the following reasons: (1) Learners who learn new words with the help of visual aids outperform those learners who use text-only dictionaries (Al-Jarf, 2007); (2) Visual information helps learners to understand complex concepts. They help the learners visualize the words in the minds and develop mental images (Wood, 2001); and (3) Visual aids also increase text comprehension and vocabulary retention through linkage of form to meaning (Hulstijn, 2001).

Clearly, nowadays, electronic dictionaries are frequently used by language learners and the use of these new types of dictionaries is becoming commonplace. However, According to Pastor and Alcina (2010), the ultimate success and achievement in vocabulary learning could not be attributed to the use of a specific type of dictionary but to the way they are used by the language learner.

\section{Method}

\subsection{Participants}

The participants of this study initially consisted of seventy-five male and female University students, ranging in age from 20 to 24 . They were in their third semester, and this study was conducted in their reading comprehension classes. The participants took part in a Preliminary English Test (PET) before the study to assess their level of proficiency and as a pre-test before the study. Based on the PET, only seventy students were selected whose scores fell one standard deviation above and below the mean and were considered as an intermediate level. The participants were assigned to two groups. The participants in the first group $(n=35)$, were supposed to use their mobile phone dictionaries (BlueDict), and those in the second group ( $n=35)$ were to use their paper dictionaries.

\subsection{Instruments}

The researchers compiled 30 texts from the Iranian National University Entrance English Exam (INUEEE). The multiple-choice test used in this study is a reliable and valid test developed by experts in in the field. The participants in the ED group used a well-known mobile dictionary called BlueDict (which include 18 different dictionaries), and the participants in the PD group used different types of PDs.

Prior to learning session, Preliminary English Test (PET) was administered in order to ensure the homogeneity of the groups. The participants' scores on PT test ranged from 40 to 50, which indicated that they were intermediate level learners. Five students were excluded from the study (two students scored much higher than the others and three students performed much lower than the others). The experimental procedure consisted of three stages: pre-test, treatment, and post-test. 
Once the homogenous samples were gathered, the participants in both groups took part in the pre-test exam. Each participant was presented with a 100 target words in a paper. The participants were supposed to write the equivalent meaning of the target words in their native language. Out of 100 words, twelve words were discarded because all the students could write the proper equivalent meaning. Consequently, eighty-eight unknown words were selected for instruction in treatment sessions.

\subsection{Treatment}

When the participants completed the pre-test stage, they were exposed to the treatment of the study which took 8 sessions. The new words were presented for the participants in the printed texts. The participants took part in this study for two sessions a week. The classes were held two sessions a week. The same teacher held both classes and the reading texts were the same too, but the participants in the ED group used their mobile dictionary and the students in the PD group used their ordinary paper dictionaries for finding the meaning of the target words.

Although the teacher provided information on different aspects of the new words, the participants of the two groups were asked to look up the target underlined words in their defined dictionaries. There are 8 kinds of different dictionaries included in BlueDict dictionary of the ED group such as Aryanpur, Longman Dictionary of American English, Advanced Persian-English Dictionary, Oxford Advanced Learners Dictionary, Cambridge Advanced Learners Dictionary, Oxford Collocations, picture Dictionary, The American Heritage Dictionary of Idioms, Longman Dictionary of Contemporary English. The participants in the ED group could listen to the audible pronunciation by a native speaker in their Longman Dictionary of Contemporary English. However, the participants in the PD group could use their paper dictionaries (monolingual and bilingual), but they could just read the written phonetic form of pronunciation.

\subsection{Post-Test}

The post-test was administered two times in the present study. The first time was immediately after the last treatment session, and the second time was with two weeks interval after the last treatment session. In both post-test sessions, the participants received the post-test without being informed to prepare themselves. The post-test was a multiple choice test with sixty items which the participants should answer in just 60 minutes under the supervision of a teacher. The first post-test was administered in order to assess the participants' short-term memory and the second delayed test (with two weeks interval) was to assess the participants' long-term retention of the target instructed words. The content of the two tests were the same but in the second test, the order of the items was changed. Two weeks interval is an optimal span for the long-term retention of the materials, which have been taught (Harris, 1969; Yongqi, 2003).

\section{Results and Findings}

In this part, the data for the two treatment groups are analyzed. The data involved two factors, Treatment and Time respectively. Treatment consisted of using Electronic Dictionary (ED) and Paper Dictionary (PD) to find the definition and meaning of target words. Time consisted of immediate time (T1), and delayed time (T2). The data in this study were gathered with the aim of finding out whether or not using ED, as compared with PD, had any effect on the vocabulary learning and retention of intermediate EFL students. To accomplish the purposes of the study, seventy university students who were considered as intermediate based on Preliminary English Test (PET), participated in this study. The participants were randomly divided into two groups. The first group $(\mathrm{n}=35)$ formed the Electronic Dictionary (ED) group and the second $(n=35)$ the PD group. After the pre-test, the participants were exposed to the treatments and an immediate posttest. After a time interval of two weeks, a delayed posttest was administered to the participants of the two groups to find out the effect of ED on long-term retention of vocabulary.

Table 1 shows the results of the PET test.

Table 1. Descriptive statistics of PET test

\begin{tabular}{llllllll}
\hline $\mathrm{N}$ & Sum & Mean & Std. deviation & Std. Error & Max & Min & K-R 21 \\
\hline 75 & 3125 & 45.36 & 3.390 & .406 & 45 & 36 & 0.85 \\
\hline
\end{tabular}

As it could be seen in Table 1, the mean score of PET test (conducted before the treatment) is 45.36. Using Kuder-Richardson formula 21, the reliability index of 0.85 was obtained which shows that the PET test was 
reliable. An independent Sample t-test was conducted before the treatment in order to compare the mean scores of the two groups. The results could be seen in Table 2 and Table 3.

Table 2. Descriptive statistics for pre-test vocabulary test

\begin{tabular}{lllllll}
\hline Group & $\mathrm{N}$ & Mean & Std. deviation & Std. Error Mean & Max & Min \\
\hline ED & 35 & 45.29 & 4.045 & .784 & 50 & 40 \\
PD & 35 & 44.75 & 4.872 & .856 & 50 & 40 \\
\hline
\end{tabular}

As it can be seen in Table 2, the mean scores of ED and PD groups are 45.29 and 44.75, respectively.

Table 3. Independent samples t-test for pretest

\begin{tabular}{lllllll}
\hline Pretest & Mean & Std. Deviation & Std. Error & $\mathrm{t}$ & $\mathrm{df}$ & Sig.(2-tailed) \\
\hline ED-PD & 3.25 & 4.125 & 1.085 & 1.750 & 27 & .075 \\
\hline
\end{tabular}

Table 3 shows the degree of significance is .075 which is more than $\alpha=.05(t(27)=1.75, p=0.75)$ which means there is no significant difference between the groups at the start of treatment and they could be considered as homogeneous.

\subsection{Results of Immediate Post-Test for PD and ED Groups}

To evaluate the effect of the treatment of the ED group and their performance on the immediate posttest, an independent sample t-test was run. Table 4 below illustrates the results obtained from this immediate post-test.

Table 4. Descriptive statistics for immediate post-test

\begin{tabular}{lllllll}
\hline Group & $\mathrm{N}$ & Mean & Max & Min & Std. deviation & Std. Error Mean \\
\hline ED & 35 & 50.75 & 56 & 41 & 3.585 & 1.156 \\
PD & 35 & 38.53 & 43 & 34 & 3.245 & .899 \\
\hline
\end{tabular}

As Table 4 shows, the mean score of immediate posttest for the ED group is 50.75, and the mean score for the PD group is 38.53. In order to check the differences and see whether the means differences are big or small, an independent sample t-test was run. Based on the results demonstrated in Table 5, the mean difference of the two groups at the time of immediate posttest was significant.

Table 5. Independent samples t-test for immediate post-test

\begin{tabular}{lllllll}
\hline Pre-test & Mean & Std. Deviation & Std. Error & $\mathrm{t}$ & $\mathrm{df}$ & Sig.(2-tailed) \\
\hline ED-PD & 4.85 & 6.856 & 1.154 & 1.45 & 27 & .028 \\
\hline
\end{tabular}

As Table 5 shows, the probability value is smaller than the level of significance, $\mathrm{P}=0.028<\alpha=.05$, $(\mathrm{t}(27)=1.45)$. Therefore, it could be concluded that there is a significant difference in vocabulary scores on the immediate posttest between the two groups.

\subsection{Results of Delayed Post-Test for PD and ED Groups}

By comparing the participants' delayed post-test score, administered after a two-week span, it could be seen whether EDs had effects on the vocabulary retention of the language learners or not. Descriptive statistics of delayed post-test in ED group and PD group are presented in Table 6. 
Table 6. Descriptive statistics for delayed post-test

\begin{tabular}{lllllll}
\hline Group & $\mathrm{N}$ & Mean & Max & Min & Std. deviation & Std. Error Mean \\
\hline ED & 35 & 55.96 & 58 & 45 & 3.457 & 0.81 \\
PD & 35 & 46.57 & 50 & 38 & 3.986 & 0.92 \\
\hline
\end{tabular}

As it could be seen in Table 6, the mean score of ED group is 55.96 and that of PD groups is 46.57. To see whether the mean difference between the two groups is significant, another independent sample t-test was run (Table 7).

Table 7. Independent samples t-test for delayed posttest

\begin{tabular}{lllllll}
\hline Post-test & Mean & Std. Deviation & Std. Error & $\mathrm{t}$ & $\mathrm{df}$ & Sig.(2-tailed) \\
\hline ED-PD & 3.75 & 6.859 & 1.582 & 2.589 & 27 & .026 \\
\hline
\end{tabular}

Based on the numerical value in Table 7, it could be clearly observed that the two groups' performance on their delayed post-test was significantly different. The Sig. value (0.026) is smaller than the alpha set value (0.05); therefore, it indicates that the type of dictionary (ED vs. PD) did have an influence on long-term retention of the new vocabularies. Consequently, it indicates that the ED group participants performed better than the PD group participants in vocabulary retention test did.

Moreover, another independent sample t-test was run in order to see whether the gender differences in this study had any effects on their new vocabulary retention. Table 8 shows the results obtained from the delayed post-test between male and female participants. The result of the independent sample t-test is presented in Table 9 .

Table 8. Descriptive statistics for delayed posttest between male and female participants

\begin{tabular}{lllllll}
\hline Group & $\mathrm{N}$ & Mean & Max & Min & Std. deviation & Std. Error Mean \\
\hline ED & 15 & 50.09 & 55 & 44 & 3.012 & 0.75 \\
PD & 20 & 47.49 & 51 & 45 & 3.526 & 0.83 \\
\hline
\end{tabular}

As it could be seen in Table 8, the mean score for the male group in the delayed posttest is 50.09 and that of female group is 47.49 . To see whether the mean difference between the two groups is significant, another independent sample t-test was run (Table 9).

Table 9. Independent samples t-test for delayed post-test between male and female groups

\begin{tabular}{lllllll}
\hline Post-test & Mean & Std. Deviation & Std. Error & $\mathrm{t}$ & $\mathrm{df}$ & Sig.(2-tailed) \\
\hline $\mathrm{M}-\mathrm{Fe}$ & 3.06 & 6.219 & 1.329 & 2.412 & 24 & .089 \\
\hline
\end{tabular}

As the results of the independent sample t-test (Table 9) shows, it could be clearly observed that the two groups' probability value is bigger than the level of significance, $\mathrm{P}=.089>.05$. Thus, it can be concluded that there is no significant difference between the mean scores of male and female participants on their delayed post-test. Therefore, it indicates that the gender differences did not have an influence on long-term retention of the new vocabularies.

\section{Discussion and Conclusion}

Mastery of vocabulary is an essential component in learning a foreign language. In Asian countries, as it was noted earlier, vocabulary is generally given little emphasis in the education curriculum (Fan, 2003). In other words, much of vocabulary instruction in classrooms is incidental (Catalan, 2003; Fan, 2003). The general practice is to immediately provide the definitions of words when a new word or phrase is encountered in a text. In this way, language learners are not encouraged to use dictionaries for learning new words (Catalan, 2003). Although the development of Electronic Dictionaries (EDs) in the past decade made them easily accessible to 
many more students all over the world, many students in Asian countries are still using printed dictionary as the reference tool in language learning. Considering these problems, the present study was an attempt to examine the effects of two different forms of dictionary on vocabulary learning of the intermediate level EFL students. The first form was the Paper Dictionary (PD) and the second form was an ED in mobile format.

The numerical data gathered in this study clearly show that Electronic Dictionaries could have a great influence on vocabulary learning and retention. The better performance of the ED group participants could be attributed to the use of ED. Therefore, it could be claimed that the learners can rely on EDs as a powerful tool for vocabulary learning and retention.

The findings of this study are in line with previous research findings (Al-Seghayer, 2001; Leffa, 1992) concerning the effect of ED in enhancing vocabulary learning. The findings of the study also support those of Bogaards (2001), and Hulstijn (1993) who found that some learners are reluctant to use their paper dictionaries when they encounter new words in the process of text comprehension. One source of this reluctance is the fact that flipping through the dictionary pages to look up the definition of new words is time-consuming and cuts the normal flow of reading. This problem is taken care of by electronic dictionaries due to their speed and ease of access. Moreover, the data of the present study supports Lauferand Hill's (2000) claim that combining the features of paper and electronic dictionaries improves vocabulary retention.

Findings of the study also reveal that vocabulary learning of L2 language learners will significantly improve when they are exposed to various presentation modes. This finding is supported by Dual-coding Theory (Paivio, 1986) which predicts that when information is coded and presented in more than a single mode, learning is enhanced. Furthermore, the findings of this study confirms the previous findings of studies carried out by such researchers as Al-Seghayer (2001); Laufer and Hill (2000); Osaki, Ochiai, Iso, and Aizawa (2003) who found the satisfactory role of ED in vocabulary learning and recall. Therefore, the overall results illustrate that a combination of aural and visual stimuli is more fruitful for learners compared to when the information is presented in a single mode (Ellis, 1994).

To conclude, the use of technology is inevitable in language classrooms. Language learners are increasingly exposed to new technological advancements and they have to make use of them in their advantage. One of the overriding benefits of the use of electronic dictionaries, as new learning tools, is that they save much precious time which is needed for other learning processes to run smoothly in text comprehension (Warschauer, 1996). This study also shows that owing to the multiple modes of presentation and interesting and eye-catching nature of electronic dictionaries, they are embraced more easily by language learners in their attempt to learn new vocabularies in a second of foreign language. The students also report more interest and motivation to learn new words when they use electronic dictionaries.

\section{References}

Aldosari, H., \& Mekheimer, M. (2010, April). Utilization of English-English online dictionaries for enhancing culture-specific translation skills in college students. Paper presented at the International Conference of Suleyman Demirel University, Building Cultural Bridges: Integrating Languages, Linguistics, Literature and Translation into Education, Almaty.

Al-Jarf, R. (2007). Teaching vocabulary to EFL college students online. CALL-EJ Online, 8(2).

Al-Seghayer, K. (2001). The effect of multimedia annotation modes on L2 vocabulary acquisition: A Comparative Study. Language Learning \& Technology, 5(1), 202-232.

Baxter, J. (1980). The dictionary and vocabulary behavior: A single word or a handful? TESOL Quarterly, 14, 325-336. http://dx.doi.org/10.2307/3586597

Bogaards, P. (2001). Lexical units and the learning of foreign language vocabulary. Studies in Second Language Acquisition, 23, 321-343. http://dx.doi.org/10.1017/S0272263101003011

Catalan, R. (2003). Sex differences in L2 vocabulary learning strategies. International Journal of Applied Linguistics, 13(1), 54-77. http://dx.doi.org/10.1111/1473-4192.00037

Chen, Y. (2011). Studies on bilingualized dictionaries: The user perspective. International Journal of Lexicography, 24(2), 161-197. http://dx.doi.org/10.1093/ijl/ecr002

Chun, D. M., \& Payne, J. S. (2004). What makes students click: Working memory and look-up behavior. System, 32, 481-503. http://dx.doi.org/10.1016/j.system.2004.09.008 
Cotter, C. (2009). Dictionaries: Harmful or helpful? Heads up English. Retrieved February 9, 2012, from http://www.headsupenglish.com/index.php?option=com_content \& task=view

Ellis, R. (1994). The study of second language acquisition. Oxford University.

Fan, M. Y. (2000). The dictionary look-up behavior of Hong Kong students: A large-scale survey. Educational Journal, 28(1), 123-138.

Fan, M. Y. (2003). Frequency of use, perceived usefulness, and actual usefulness of second language vocabulary strategies: A study of Hong Kong learners. Modern Language Journal, 222-241. http://dx.doi.org/10.1111/1540-4781.00187

Gonzalez, O. (1999). Building vocabulary: Dictionary consultation and the ESL student. Journal of Adolescent \& Adult Literacy, 43(3), 264.

Gu, Y., \& Johnson, R. K. (1996). Vocabulary learning strategies and language learning outcomes. The Modern Language Learning, 46(4), 643-679. http://dx.doi.org/10.1111/j.1467-1770.1996.tb01355.x

Harris, D. P. (1969). Testing English as a second language. New York, McGraw Hill Book Company.

Hartmann, R. R. K. (1991). What's the use of learners' dictionaries? Institute of Language in Education Journal, $8,73-83$.

Hulstijn, J. H. (1993). When do foreign-language readers look up the meaning of unfamiliar words? The influence of task and learner variables. The Modern Language Journal, 77(2), 139-147. http://dx.doi.org/10.1111/j.1540-4781.1993.tb01957.x

Hulstijn, J. H. (2001). Intentional and incidental second language vocabulary learning: A reappraisal of elaboration, rehearsal, and automaticity. In P. Robinson (Ed.), Cognition and second language instruction (pp. 258-286). Cambridge: Cambridge University Press. http://dx.doi.org/10.1017/CBO9781139524780.011

Hulstijn, J. H., Hollander, M., \& Greidanus, T. (1996). Incidental vocabulary learning by advanced foreign language students: The influence of marginal 107 glosses, dictionary use, and reoccurrence of unknown $\begin{array}{lllll}\text { words. } & \text { The } & \text { Modern } & \text { Language }\end{array}$ http://dx.doi.org/10.1111/j.1540-4781.1996.tb01614.x

Kaalep, H., \& Mikk, J. (2008). Creating specialized dictionaries for foreign language learners: A case study. International Journal of Lexicography, 21(4), 369-394. http://dx.doi.org/10.1093/ijl/ecn017

Knight, S. (1994). Dictionary use while reading: The effects on comprehension and vocabulary acquisition for students of different verbal abilities. The Modern Language Journal, 78(3), 285-299. http://dx.doi.org/10.1111/j.1540-4781.1994.tb02043.x

Kobayashi, C. (2006). The use of pocket electronic dictionaries as compared with 109 printed dictionaries by Japanese learners of English (Unpublished doctoral dissertation). Ohio State University, USA.

Kojic-Sabo, I., \& Lightbown, P. M. (1999). Students' approaches to vocabulary learning and their relationship to success. The Modern Language Journal, 83(2), 176-192. http://dx.doi.org/10.1111/0026-7902.00014

Krashen, S. (2003). Explorations in language acquisition and use. Portsmouth NH, Heinemann.

Laufer, B., \& Hill, M. (2000). What lexical information do L2 learners select in a CALL dictionary and how does it affect word retention? Language Learning \& Technology, 3(2), 58-76. Retrieved February 29, 2012, from http://llt.msu.edu/vol3num2/laufer-hill/index

Leffa, V. J. (1992). Making foreign language texts comprehensible for beginners: An experiment with an electronic glossary. System, 20(1), 63-73. http://dx.doi.org/10.1016/0346-251X(92)90008-Q

Levow, G., Oard, D., \& Resnik, P. (2005). Dictionary-based techniques for cross-language information retrieval. Information Processing \& Management, 41(3), 523-547. http://dx.doi.org/10.1016/j.ipm.2004.06.012

Luppescu, S., \& Day, R. (1993). Reading, dictionaries, and vocabulary learning. Language Learning, 43(2), 263-287. http://dx.doi.org/10.1111/j.1467-1770.1992.tb00717.x

Mansoor-ul-Haq, H., \& Ahmad, A. (2010). Purpose of dictionary use in professional education: A study of dictionary using habits in medical students. Procedia Social and Behavioral Sciences, 2, 3988-3993. http://dx.doi.org/10.1016/j.sbspro.2010.03.628

McCarthy, M. J. (1990). Vocabulary. Oxford: Oxford University Press. 
Nation, I. S. P. (2001). Learning vocabulary in another language. Cambridge: Cambridge University Press. http://dx.doi.org/10.1017/CBO9781139524759

Nesi, H. (1999). A user's guide to electronic dictionaries for language learners. International journal of lexicography, 12(1), 55-66. http://dx.doi.org/10.1093/ij1/12.1.55

Nesi, H. (2003). The specification of dictionary reference skills in higher education. In R. R. K. Hartmann (Ed.), Lexicography-Critical concepts: Dictionaries, compilers, critics and users (pp. 370-393). London and New York: Routledge.

Nesi, H. (2008). Dictionaries in electronic form. In A. P. Cowie (Ed.), The Oxford history of English lexicography (pp. 458-478). Oxford: Oxford University Press.

Nesi, H., \& Meara, P. (1994). Patterns of misrepresentation in the productive use of EFL dictionary definitions. System, 22(1), 1-15. http://dx.doi.org/10.1016/0346-251X(94)90036-1

Neubach, A., \& Cohen, A. D. (1988). Processing strategies and problems encountered in the use of dictionaries. Journal of the Dictionary Society of North America, 10, 1-19. http://dx.doi.org/10.1353/dic.1988.0018

Nielsen, S. (2010). Specialized translation dictionaries for learners. In P. A. Fuertes-Olivera (Ed.), Specialized dictionaries for learners (pp. 69-82). Berlin and New York: De Gruyter. http://dx.doi.org/10.1515/9783110231335.1.69

Paivio, A. (1986). Mental representations: A dual coding approach. Oxford, England: Oxford University Press.

Ooi, D., \& Kim-Seoh, J. L. (1996). Vocabulary teaching: Looking behind the word. ELT Journal, 50(1), 52-58. http://dx.doi.org/10.1093/elt/50.1.52

Osaki, S., Ochiai, N., Iso, T., \& Aizawa, K. (2003). Electronic dictionary vs. printed dictionary: Accessing the appropriate meaning, reading comprehension, and retention. Proceedings of ASIALEX, 3, 205-212.

Pastor, V., \& Alcina, A. (2010). Search techniques in electronic dictionaries: A classification for translators. International Journal of Lexicography, 23(3), 307-354. http://dx.doi.org/10.1093/ijl/ecq015

Schmitt, N. (1997). Vocabulary learning strategies. In N. Schmitt, \& M. McCarthy (Eds.), Vocabulary description, acquisition and pedagogy (pp. 199-227). Cambridge: Cambridge University Press.

Schmitt, N. (2000). Vocabulary in language teaching. Cambridge: Cambridge University Press.

Stahl, S. A., \& Fairbanks, M. (1986). The effects of vocabulary instruction: A model-based meta-analysis. Review of Educational Research, 56, 72-110. http://dx.doi.org/10.3102/00346543056001072

Stirling, J. (2005). The portable electronic dictionary: Faithful friend or faceless foe? Modern English Teacher, 14(3), 64-72.

Thompson, G. (1987). Using bilingual dictionaries. ELT Journal, 41, 282-286. http://dx.doi.org/10.1093/elt/41.4.282

Tillyer, A. (2003). Portable electronic dictionaries [electronic version]. TESL-L, 24.

Warschauer, M. (1996). Motivational aspects of using computers for writing and communication. Telecollaboration in foreign language learning, 29-46.

Wesche, M., \& Paribakht, T. S. (1999). Incidental L2 vocabulary acquisition: Theory, current research, and instructional implications. Studies in Second Language Acquisition, 21, 175-335.

Wood, J. (2001). Can software support children's vocabulary development? Language Learning \& Technology, $5(1), 166-201$.

Yongqi Gu, P. (2003). Vocabulary learning in a second language: Person, task, context and strategies. TESL-E J, $7(2), 1-28$.

\section{Copyrights}

Copyright for this article is retained by the author(s), with first publication rights granted to the journal.

This is an open-access article distributed under the terms and conditions of the Creative Commons Attribution license (http://creativecommons.org/licenses/by/3.0/). 